\title{
A reinterpretation of the cytoarchitectonics of the telencephalon of the Comoran coelacanth
}

\author{
R. Glenn Northcutt ${ }^{1,2 *}$ and Agustín González ${ }^{3}$ \\ 1 Laboratory of Comparative Neurobiology, Scripps Institution of Oceanography, University of California San Diego, La Jolla, CA, USA \\ 2 Department of Neurosciences, School of Medicine, University of California San Diego, La Jolla, CA, USA \\ ${ }^{3}$ Department of Cell Biology, Faculty of Biology, University of Complutense of Madrid, Madrid, Spain
}

Edited by:

Fernando Martinez-Garcia, Universidad de Valencia, Spain

Reviewed by:

Rudolf Nieuwenhuys, Netherlands Institute for Neuroscience, Netherlands Ramon Anadon, Universidad de Santiago de Compostela, Spain

\section{*Correspondence}

R. Glenn Northcutt, Department of Neurosciences, University of California San Diego, 9500 Gilman Drive, La Jolla, CA 92093-0201, USA.

e-mail: rgnorthcutt@ucsd.edu
The cytoarchitecture of the telencephalon of the Comoran coelacanth, Latimeria chalumnae, was analyzed in the context of recent advances in our understanding of telencephalic organization in lungfishes and amphibians, which constitute the sister group to coelacanths. In coelacanths, the telencephalon is divided into pedunculated olfactory bulbs, paired hemispheres, and an unevaginated telencephalon impar. The hemispheres consist of a ventrally located subpallium and, dorsally, a greatly expanded pallium. Traditionally, the subpallium in coelacanths has been divided into a medial septal area and a lateral striatum. Re-examination of the lateral subpallial wall, however, suggests that the striatum is more restricted than previously believed, and it is replaced dorsally by a more scattered plate of cells, which appears to represent the ventral pallium. The putative ventral pallium is continuous with a ventromedial pallial formation, which appears to receive input from the lateral olfactory tract and should be considered a possible homolog of the lateral pallium in tetrapods. The putative lateral pallium is replaced by a more dorsomedial pallial formation, which may represent the dorsal pallium. This formation is replaced, in turn by an extensive lateral pallial formation, which appears to be homologous to the medial pallium of tetrapods. An expanded medial pallium in coelacanths, lepidosirenid lungfishes, and amphibians may be related to well developed spatial learning. Traditionally, the telencephalon impar of coelacanths, has been interpreted as an enlarged preoptic area, but reanalysis indicates that the so-called superior preoptic nucleus actually consists of the medial amygdalar nucleus.

Keywords: amygdala, Latimeria, lobe-finned fishes, medial pallium, ventral pallium

\section{INTRODUCTION}

During the Devonian, approximately 415 to 360 million years ago, the Sarcopterygii (lobe-finned fishes) constituted one of two major radiations of bony fishes. Today, only three groups of Sarcopterygii still exist: the coelacanths, the lungfishes, and the limbed vertebrates (Tetrapoda). All recent phylogenetic data indicate that lungfishes are the sister group of tetrapods, and that coelacanths are, in turn, the sister group of these taxa (Brinkmann et al., 2004; Takezaki et al., 2004). There are only two known living coelacanth species: the Comoran coelacanth, Latimeria chalumnae, and the Indonesian coelacanth, L. menadoensis. Both species are 1-2 $\mathrm{m}$ in length and weigh $65-100 \mathrm{~kg}$. Both inhabit marine rocky slopes with caves at depths of 100-700 m. L. chalumnae was discovered in 1938, and over 100 specimens have been preserved in museums internationally. Their current population, however, is estimated to be less than 400 individuals (Hissmann et al., 1998). L. menadoensis was discovered only in 1997, and there are no estimates of their population size.

Although the anatomy of L. menadoensis has not been described, the general anatomy of L. chalumnae is known in detail (Millot and Anthony, 1958, 1965; Millot et al., 1978), and there are several descriptions of the brain, including detailed reports on cell groups and major pathways (Nieuwenhuys, 1965, 1998; Nieuwenhuys et al., 1977; Nieuwenhuys and Meek, 1990). However, recent molecular and connectional advances in the study of telencephalic organization in lungfishes (González and Northcutt, 2009; Northcutt, 2009) and amphibians (Marín et al., 1998; González et al., 2002; Brox et al., 2003,2004; Moreno and González, 2004, 2005, 2006, 2007a,b) reveal that these taxa possess four, not three, pallial divisions and that the amygdalar complex consists of at least three distinct nuclei. For these reasons, the cytoarchitecture of the telencephalon of the Comoran coelacanth was reevaluated, with a particular focus on pallial and amygdalar organization.

\section{MATERIALS AND METHODS ANIMALS AND TISSUE PROCESSING}

Two brains of $L$. chalumnae were dehydrated, paraffin embedded, and cut into $15 \mu \mathrm{m}$ serial sections in the transverse plane. The first brain was donated by the Field Museum of Natural History, Chicago, IL, USA (CCC number 61 of Bruton and Coutouvidis, 1991). Unfortunately, the body of this coelacanth was frozen prior to fixation, and the brain histology is marginal. The second brain was dissected from specimen 80 (Bruton and Coutouvidis, 1991) and fixed in $4 \%$ paraformaldehyde shortly after death, and the brain histology is very good. The serial sections of this brain were divided into three series: One series was stained with the Bodian silver method to reveal myelinated and unmyelinated fiber tracts; A second series was stained with $1 \%$ cresyl violet to reveal neuronal cell bodies; The third series was stained with the Klüver-Barrera method to reveal myelinated tracts and neuronal cell bodies. 


\section{CYTOARCHITECTONIC CRITERIA}

Six criteria are commonly used to recognize cell groups cytoarchitectonically: (1) differences in neuronal cell size; (2) differences in neuronal density; (3) relatively cell-free zones, which frequently indicate boundaries between cell groups; (4) differences in the distribution of genetic and immunohistochemical markers; (5) differences in the connectivity of the suspected cell groups; and (6) phylogenetic continuity of cellular groups and their molecular markers and connections within a clade. Frequently, when a brain region is first examined cytologically, the first three criteria are primarily used to generate hypotheses regarding the number of cell groups, their topology, and their possible homologs in other taxa. Ideally, these hypotheses are then tested using criteria 4 and 5. Criterion 6 is critical at both levels of analysis. Firstly, it has a predictive function at the first level of analysis, as brain organization within a clade is generally conserved, and cell groups that occur within members of a clade should be widely, if not universally, present (plesiomorphs) and can be predicted to occur in a member of the clade that has not yet been examined. Secondly, this criterion is critical in proposing homologies between cell groups in different members of a clade, as a cell group and its molecular and hodological characteristics should be widely, if not universally, present (plesiomorphs), or they should exhibit linear transformation (apomorphs) within the clade.

Unfortunately, in the case of the Comoran coelacanth, there are no molecular or hodological data to aid in proposing and evaluating hypotheses of the homology of neuronal cell groups. Thus, criteria $1-3$, aided by the predictive power of criterion 6 , are all that is presently available on which to base hypotheses regarding individual cell groups and their possible homology with cell groups in other taxa of lobe-finned fishes. For this reason, all statements regarding the recognition of cell groups in the telencephalon of the Comoran coelacanth, and their possible homologs in other taxa, can be only considered tentative. Hopefully they will be tested when molecular data becomes available, but given the rarity and endangered status of coelacanths, it may never be possible to undertake hodological experiments.

\section{RESULTS}

The olfactory bulbs were not collected with either of the brains so the cytoarchitecture of only the telencephalic hemispheres and the telencephalon impar is described. The olfactory bulbs lie immediately adjacent to the olfactory organs, so that the olfactory nerves are very short. The axons of the olfactory bulb collect as slender olfactory peduncles, which may be as long as $20 \mathrm{~cm}$ and can be traced caudally into the most rostral division of the telencephalic hemispheres, which form distinct lobes termed the rostral bodies (Figures 1A,B and 2A,B).

\section{ROSTRAL BODIES}

Each rostral body consists of a medial ependymal surface with scattered neurons that surround a dense core of secondary olfactory fibers (Figures 2A,B). These fibers arise from the olfactory peduncles, which divide into dorsally and ventrally situated tracts - i.e., the lateral and medial olfactory tracts (Figure 2B) as each peduncle enters the ipsilateral rostral body along its lateral margin. Although the fibers of the olfactory peduncle initially divide into dorsal and ventral tracts as they course along the lateral margin of the rostral bodies (Figures 2A,B), these tracts are interpreted as homologous to the lateral and medial olfactory tracts of tetrapods, based on their subsequent trajectories in the telencephalic hemispheres. The fibers of both secondary olfactory tracts densely ramify within the rostral body, and it is clear that this body primarily receives olfactory input. The secondary olfactory tracts can be clearly distinguished from one another by their relative positions in the rostral body, and also by differences in fiber size, as fibers in the lateral olfactory tract are far more robust.

Many of the fibers of the medial olfactory tract terminate within the ventral half of the rostral body, but a number of these fibers continue more caudally and appear to innervate the subpallium of the rostral pole of the more caudal telencephalic hemisphere. The lateral olfactory tract, in addition to innervating the dorsal half of the rostral body, continues caudally as a distinct tract and enters the rostral pallium of the telencephalic hemisphere, where it can be traced medially into the core of the pallium (Figure 2C).

The rostral bodies appear to be pallial in origin, as caudally each rostral body is gradually replaced by the cell groups that form the rostral pallial telencephalon (Figure 2C). The cells of the dorsolateral rostral body are the first to be replaced by the larger cells of the medial pallium. Slightly more caudally the dorsomedial cells of the rostral body are replaced by the cells of the dorsal pallium, which at this level (Figure 2C) are embedded in a pale-staining neuropil. There is no distinct border between the ventral cells of the rostral body and those of the lateral pallium, only a gradual transition from one cell group to the other, marked by an expansion of the lateral olfactory tract.

\section{TELENCEPHALIC HEMISPHERES}

The telencephalic hemispheres of the Comoran coelacanth are clearly evaginated, with the subpallium consisting primarily of a distinct periventricular cellular plate, and the pallium comprising a massive lobe, which appears to have protruded into the lateral ventricle (Figure 1D). There is thus little evidence that the pallium participated in the extensive evagination that characterizes the subpallium.

A number of divisions of the subpallium can be recognized by differences in the thickness of its periventricular cellular plate. Medially, the periventricular plate lies very close to the ependymal lining of the ventricle and is approximately four to five cells in thickness, with the exception of a distinct cluster of neurons which occurs adjacent to the lamina terminalis (Figure 1D). The topology of the medial periventricular plate, and the migrated cell group at the border of the lamina terminalis, suggest that these cell groups are homologous to the lateral and medial septal nuclei, respectively, in other lobe-finned fishes.

As the subpallial periventricular plate is traced laterally, the plate becomes more distal to the ependymal layer of the lateral ventricle and thickens to approximately 10 cells (Figures 1D and 2D). It continues to thicken as it is traced laterally, as does the entire wall of the subpallium, so that the periventricular plate forms a distinct ventrolaterally directed cellular prominence with the deeper subpallial wall, bulging into the lateral ventricle (Figures 1D,E). This cellular prominence may mark the boundary 
A

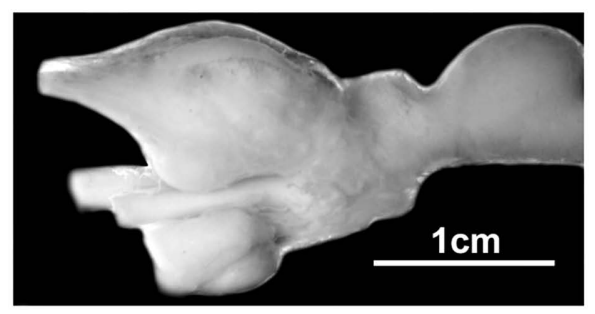

B
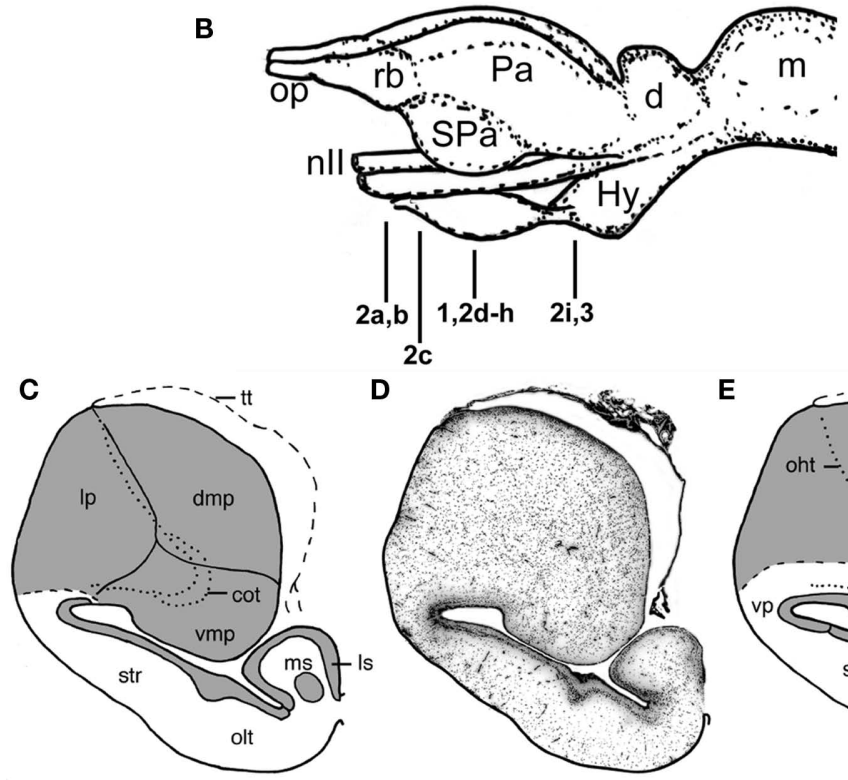

D

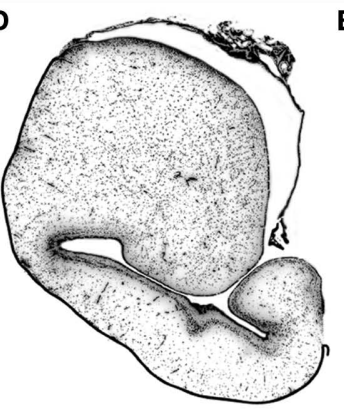

$\mathbf{E}$

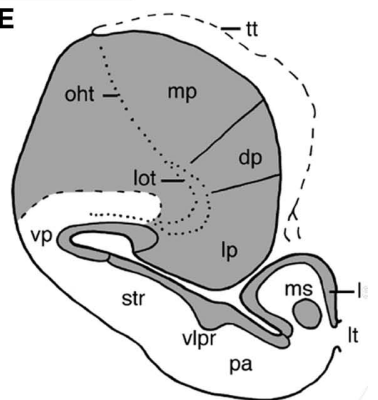

FIGURE 1 The forebrain and midbrain the Comoran coelacanth. (A) Photograph of a lateral view of the forebrain and midbrain. (B) Line drawing of the lateral view, indicating the levels of the transverse section in Figures 1-3. (C) Line drawing of a transverse section through one telencephalic hemisphere showing the boundaries of cell groups interpreted by Nieuwenhuys (1965) and Nieuwenhuys and Meek (1990). (D) A Nissl-stained section from the present study, showing the actual histology. (E) Line drawing indicating the boundaries of the cell groups as interpreted in the present study. Dotted lines in (C,E) indicate the lateral olfactory and olfactohabenular tracts. Short, heavy dashed lines indicate the subpallial-pallial boundary (C) or the boundary between the neuropil of the ventral pallium and the medial pallium (E). cot, Central olfactory tract; $d$, diencephalon; dmp, dorsomedial pallium; dp, dorsal pallium; Hy, hypothalamus; Hyp, hypophysis; lot, lateral olfactory tract; lp, lateral pallium; Is, lateral septum; It, lamina terminalis; $\mathrm{m}$, mesencephalon; $\mathrm{mp}$, medial pallium; $\mathrm{ms}$, medial septum; nll, optic nerve; oht, olfactohabenular tract; olt, olfactory tubercle; op, olfactory peduncle, $\mathrm{Pa}$ (in lateral view), pallium; pa (in transverse section), pallidum; rb, rostral body; SPa, subpallium; str, striatum; tt, telencephalic tela; vlpr, ventrolateral cellular prominence; vmp, ventromedial pallium; vp, ventral pallium. between a dorsally situated striatum and a more ventrally situated pallidum, but this interpretation remains speculative without immunohistochemical data.

As the subpallial periventricular cellular plate is traced further laterally and dorsally, its characteristics again change. Near the extensive recess of the lateral ventricle, which appears to separate the subpallium and pallium, its cells become more scattered (Figure 1D), and they take on a typical pallial appearance dorsal to the lateral ventricular recess (Figure 2E). The topology and cellular organization of the subpallial periventricular plate suggest that this region is not part of the subpallium but is, rather, the ventral most division of the pallium, termed the ventral pallium in tetrapods.

The remaining three divisions of the pallium (the medial, dorsal, and lateral divisions) traditionally recognized in other lobed-finned fishes are clearly evident in the Comoran coelacanth. These divisions and their topology are most obvious in the rostral pole of the pallium (Figure 2C). The medial pallium is the most dorsally situated pallial division and, as in other lobe-finned fishes, it is continuous with the even more dorsally situated telencephalic tela
(Figure 2C). At this level, the dorsal pallium appears to be a division of the pallium sandwiched between the more dorsolaterally situated medial pallium and the more ventrally situated lateral pallium. The cells of the dorsal pallium are smaller than those of either the medial or lateral pallial divisions and are surrounded by a paler staining neuropil (Figure 2C). At this level, the lateral pallium occupies the ventral half of the rostral pallial lobe, and its core consists of numerous fascicles of the lateral olfactory tract (Figure 2C), which appear to radiate into all three pallial divisions.

More caudally, the lateral pallium appears to be displaced from the lateral pial surface by the medial pallium (Figures 1D,E), but it is laterally continuous with the putative ventral pallium and is still bordered dorsally by the dorsal pallium. The lateral pallium at mid-hemispheric levels consists of a core of fascicles of the lateral olfactory tract and a neuropil surrounded by a more periventricularly located band of cells that is many times thicker than the central neuropil when seen in the transverse plane (Figure 2F). It has not been possible to trace fascicles of the lateral olfactory tract into the periventricular cellular band. Even at mid-hemispheric levels, 

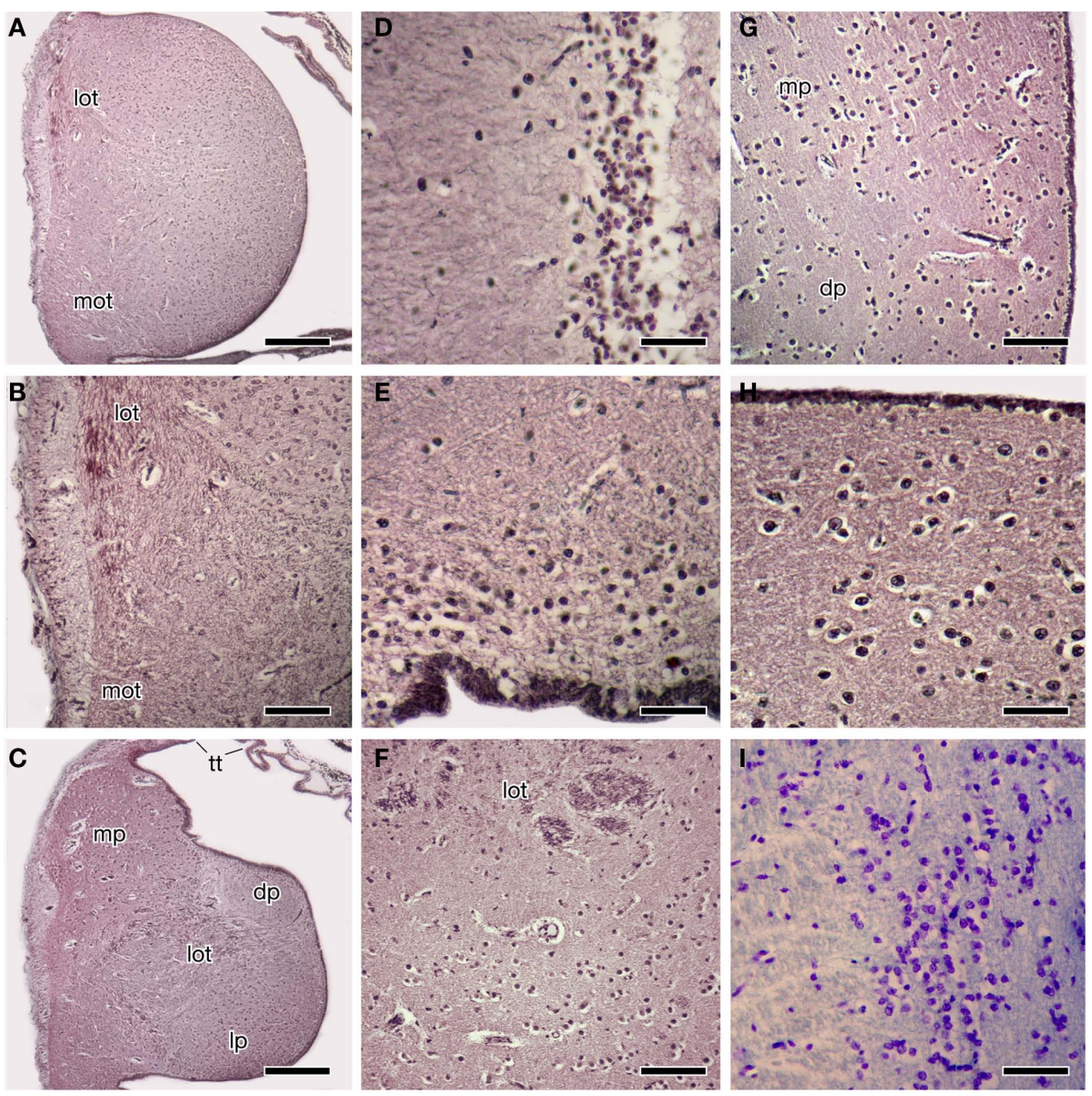

FIGURE 2 | Photomicrographs of transverse sections through the forebrain of the Comoran coelacanth showing various cell groups. $(A, B)$ The rostral body. (C) The rostral pallium. (D) The striatum. (E) The ventral pallium. (F) The core and cellular band of the lateral pallium. (G) The medial border of the dorsal and medial pallia. (H)The cells of the medial pallium. (I)
The cells of the central amygdalar nucleus. Sections in (A-H) are stained by the Bodian silver method; section I is stained with $1 \%$ cresyl violet. Scale bars = $100 \mu \mathrm{m}$ (D,E,H,I), $200 \mu \mathrm{m}$ (B,F,G), $500 \mu \mathrm{m}$ (A,C). dp, Dorsal pallium; lot, lateral olfactory tract; Ip, lateral pallium; mot, medial olfactory tract, $\mathrm{mp}$, medial pallium; tt telencephalic tela. fascicles of the lateral olfactory tract can still be seen more laterally within the neuropil of the ventral pallium. The ventral pallium can be divided into a periventricularly located cell plate and a more superficial molecular layer (Figures 1D,E) which can be clearly distinguished from the adjacent neuropil of the medial pallium.

Throughout its rostrocaudal extent, the dorsal pallium can be distinguished from the lateral and medial pallia, because its cells are more scattered than those of the other two divisions (Figure 2G). Furthermore, even though the dorsal pallial cells are more scattered, their lamination is more distinct than that of cells in either the lateral pallium or the medial pallium. The cellular density of the medial pallium is at least twice that of the dorsal pallium (Figure 2G). The cells of the medial pallium also are larger and are embedded in a denser neuropil consisting of larger fibers (Figure 2H).

At caudal hemispheric levels, the pallial lobe has a deep horizontal sulcus along its medial edge, which clearly separates the dorsal and medial pallia from the lateral pallium. At this level, the periventricular cellular band of the lateral pallium decreases in crosssectional thickness and forms a distinct periventricular cellular plate, which almost completely encircles the core of fascicles of the lateral olfactory tract. Lamination of the dorsal pallium also becomes more distinct, with the laminae being broader dorsally than ventrally as the caudal border of the dorsal pallium is reached. The medial pallium becomes narrower in cross-sectional thickness but appears to end more caudally in the telencephalon impar (Figure 3B).

\section{TELENCEPHALON IMPAR}

The telencephalon impar of the Comoran coelacanth is an unevaginated caudal part of the telencephalon, which forms a simple tube whose floor is formed rostrally by the optic chiasm and the walls of the preoptic recess of the third ventricle. Its lateral walls are slightly thickened, whereas its roof consists of a non-neural ependymal transverse velum (Figure 3). Unlike the situation in other vertebrates, the infundibulum of the hypothalamus and the hypophysis extend rostrally rather than caudally, apparently due to a general caudal shift of the rest of the brain during development. As a result, the infundibulum of the hypothalamus is located beneath the rostral most edge of the optic chiasm, and the ventral hypothalamus extends further rostral than in most vertebrates (Figures 1A,B and 3). Despite this distortion in the hypothalamus, the preoptic recess and adjacent preoptic nuclei 

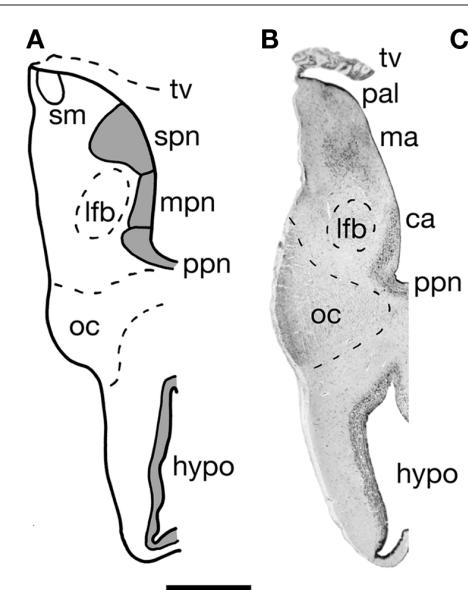

c

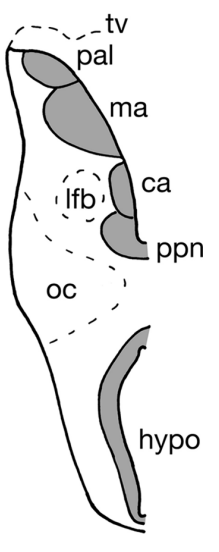

FIGURE 3 |A transverse section through one half of the telencephalon impar of the Comoran coelacanth. (A) Cell groups as interpreted by Nieuwenhuys (1965). (B) A Nissl-stained section from the present study showing the histology. (C) Cell groups as interpreted in the present study. Bar scale = $1 \mathrm{~mm}$. ca, Central amygdalar nucleus; hypo, hypothalamus; Ifb, lateral forebrain bundle; ma, medial amygdalar nucleus; mpn, magnocellular preoptic nucleus; oc, optic chiasm; pal, pallium; ppn, parvocellular preoptic nucleus; stria medullaris; spn, superior preoptic nucleus; tv, transverse velum.

appear unaffected. A parvocellular preoptic nucleus, composed of small densely packed neurons, can be traced dorsal to the optic chiasm, where it is replaced more caudally by the much larger cells of the magnocellular preoptic nucleus. More rostrally, a more scattered group of neurons (Figures 2I and 3B) occurs dorsal to the parvocellular preoptic nucleus. This cell group appears to be homologous to the central amygdalar nucleus of lungfishes and tetrapods (Figures 3B,C), which is also located adjacent to the lateral forebrain bundle and consists of the largest cells in the vicinity. More dorsally, the putative central amygdalar nucleus is replaced, in turn, by a group of smaller cells, which appears to be homologous to the medial amygdalar nucleus of lungfishes and tetrapods (Figures 3B,C). Although the topology and cytology of these nuclei in the Comoran coelacanth are consistent with the interpretation that they are homologs of amygdalar nuclei in other lobe-finned fishes, these hypotheses would be greatly supported by immunohistochemical data.

\section{DISCUSSION}

Our reinterpretation of the telencephalic cytoarchitectonics of the Comoran coelacanth generally agrees with the earlier studies of Nieuwenhuys and colleagues (Nieuwenhuys, 1965, 1998; Nieuwenhuys et al., 1977; Nieuwenhuys and Meek, 1990), but differs regarding four points: (1) the pallial-subpallial border and the recognition of a putative ventral pallium; (2) the organization of the striatum; (3) the borders of the medial pallium; and (4) the organization of the amygdala. Each of these points is discussed below.

\section{PALLIAL-SUBPALLIAL BORDER}

Nieuwenhuys and colleagues recognized the lateral pallial-subpallial border as occurring just dorsal to the lateral recess of the lateral ventricle (Figure 1C), and they interpreted the ventrolateral wall as homologous to the striatum of other lobe-finned fishes.
Re-examination of the ventrolateral wall of the Comoran coelacanth suggests that the periventricular cellular plate that characterizes the striatum changes as it is traced dorsally and transforms to a cell group typical of the pallium, and we have therefore recognized it as a putative ventral pallium (Figure 1E). This interpretation is supported by new immunohistochemical data (Brox et al., 2003, 2004; Moreno et al., 2008; González and Northcutt, 2009) indicating that the pallium in the lobe-finned fish radiation (i.e., lobe-finned fishes and tetrapods) consists of not three but four pallial divisions, with the ventral pallium interposed between the lateral pallium and the striatum. As in other lobe-finned fishes, there is cytological evidence that the ventral pallium in the Comoran coelacanth may consist of dorsal and ventral subdivisions, which may be homologous to the dorsal ventricular ridge and lateral amygdalar nucleus, respectively, in amniotic vertebrates. This speculation, however, needs to be confirmed by molecular markers which have clearly delineated these cell groups in other lobe-finned fishes.

\section{STRIATAL ORGANIZATION}

The striatopallidal system of tetrapods is now believed to comprise a dorsal system, the dorsal striatum and dorsal pallidum, and a ventral system, the nucleus accumbens plus the olfactory tubercle and a ventral pallidum (Heimer et al., 1995; Marín et al., 1998). Similar systems have recently been recognized in lungfishes (González and Northcutt, 2009; Northcutt, 2009), but it is still unclear whether or not separate dorsal and ventral pallidal cell groups exist. In any case, the striatum recognized by Nieuwenhuys and colleagues, and in the present analysis of the Comoran coelacanth, appears to be homologous to the dorsal striatum of other lobe-finned fishes. However, the ventral striatum (olfactory tubercle) recognized by Nieuwenhuys and colleagues at mid-hemispheric levels (Figure 1C) appears to be far too caudal to represent the ventral striatum of other lobe-finned fishes. Based on the topology of the cell group, and the presence of a distinct ventrolateral cellular prominence dividing the ventrolateral hemispheric wall, this cell group is more parsimoniously interpreted as the pallidum (Figure 1E), although it is presently unclear whether it represents both pallidal cell groups or only the dorsal pallidum of other lobe-fined fishes (this situation is very similar to that observed in the subpallium of urodeles, Moreno and González, 2007a). Once again, there are molecular markers, such as DARPP-32, that could clarify these issues.

\section{MEDIAL PALLIAL BORDERS}

Nieuwenhuys (1965) recognized three pallial divisions in the Comoran coelacanth: his dorsomedial, ventromedial, and lateral pallia (Figure 1C). He noted that suspected secondary olfactory fibers, which he termed the central olfactory tract, penetrate the core of his ventromedial pallial division. Further, he concluded that the ventromedial pallium was probably homologous to the lateral pallium in other lobe-finned fishes (Nieuwenhuys, 1998). He concluded, however, that his dorsomedial and lateral pallial divisions could not be homologous to the dorsal and medial pallia in other vertebrates on topological grounds. We disagree with this conclusion. If the ependymal surface is followed dorsally, a second pallial division, which we interpret as a putative dorsal pallium, replaces the lateral pallium (Figure 1E). In turn, a putative dorsal pallium is replaced by a third pallial division, which we interpret as 
a putative medial pallium. As in other vertebrates, the telencephalic tela attaches at the pial-ependymal border (Figures 1C-E). Thus, topological relationships of the pallial divisions in the Comoran coelacanth are preserved along the ependymal surface. This is not the case, however, along the pial surface. In other vertebrates, the pallial divisions show a dorsoventral sequence from medial pallium, to dorsal pallium, to lateral pallium, to ventral pallium. In the Comoran coelacanth, the putative medial pallium borders the putative ventral and lateral pallia, as well as the putative dorsal pallium (Figure 1E). This topological distortion could have occurred by an outward bending (eversion) of the developing pallial wall, coupled with a secondary fusion of the closely opposed pial surfaces of the lateral and medial pallia, as a secondary fusion of the caudal telencephalic wall with the rostral wall of the diencephalon is known to occur in hagfishes (Wicht and Northcutt, 1992). There is no histological trace of such an eversion and secondary fusion of the pallial walls in the Comoran coelacanth, however, and the simplest explanation is that the developing medial pallium has expanded rostrally and medially, displacing the putative lateral pallium and secondarily contacting the putative ventral pallium. Where there is a distinct difference in the texture of the neuropils of the putative medial and ventral pallia (Figure 1E).

We also differ from Nieuwenhuys and colleagues concerning the boundary between the putative dorsal and medial pallia (Figures 1C,E). Nieuwenhuys (1965) indicated that this boundary was marked by a cell-free zone, whereas we believe it is marked by a sharp change in cellular density (Figure 2G). It appears that Nieuwenhuys focused on the position of the olfactohabenular tract to mark the border between his lateral and dorsomedial pallial divisions (Figure 1C), whereas we have focused on cell density as an indicator of the putative dorsal-medial pallial border (Figure 1E). In either case, however, the putative medial pallium of the Comoran coelacanth occupies an extensive segment of the pallium, equal to or much larger than the lateral pallium. Although few details are known about the general biology of the Comoran coelacanth, it is well documented that these fish return to marine caves during the day and that the same individuals have been identified in the same caves for several years (Fricke et al., 1991). Highly developed spatial learning is also documented in amphibians (Wells, 2007) as well, and also appears to be well developed in the lepidosirenid lungfish Protopterus (Greenwood, 1987). Thus it is possible that an expanded medial pallium and its associated circuitry mediates spatial learning in coelacanths as in other lobe-finned fishes.

\section{AMYGDALAR ORGANIZATION}

Following Rudebeck's (1945) description of the telencephalon impar in a lungfish, Protopterus, Nieuwenhuys $(1965,1998)$ divided the telencephalon impar of the Comoran coelacanth into an inferior preoptic nucleus and a superior preoptic nucleus. He further divided the inferior preoptic nucleus in a parvocellular nucleus and a magnocellular nucleus (Figure 3A). Like Rudebeck, Nieuwenhuys also concluded

\section{REFERENCES}

Brinkmann, H., Venkatesh, B., Brenner, S., and Meyer, A. (2004). Nuclear proteincoding genes support lungfish and not the coelacanth as the closest liv- ing relatives of land vertebrates. Proc. Natl. Acad. Sci. U.S.A. 101, 4900-4905. Brox, A., Puelles, L., Ferreiro, B., and Medina, L. (2003). Expression of the genes GAD67 and distal-less-4 in the

that the superior preoptic nucleus was probably homologous to the caudal part of the strio-amygdaloid complex in tetrapods. Studies of lungfishes (González and Northcutt, 2009; Northcutt, 2009; González et al., 2010) and tetrapods (Moreno and González, 2004, 2005, 2006, $2007 \mathrm{a}, \mathrm{b}$ ) have clearly established that the amygdalar complex consists of at least central, lateral, and medial nuclei.

The Comoran coelacanth also appears to exhibit this same pattern of amygdalar organization. As already noted, a putative ventral pallium can be recognized, and the ventral subdivision of this pallial division is most likely homologous to the lateral amygdalar nucleus in lungfishes and tetrapods. Based on cytology and topography, however, we believe that the nucleus identified as the magnocellular preoptic nucleus by Nieuwenhuys (Figure 3A) is actually homologous to the central amygdalar nucleus of lungfishes and tetrapods (Figures 3B,C). Another nucleus in the preoptic region of the Comoran coelacanth that is slightly more caudal and ventral appears to be a more likely candidate for a homolog of the magnocellular preoptic nucleus. This nucleus comprises larger, more compact cells that are located periventricularly, as in other lobe-finned fishes, and is thus a more likely homolog of the magnocellular preoptic nucleus than that recognized by Nieuwenhuys $(1965,1998)$.

We do agree with Rudebeck (1945) and Nieuwenhuys (1965, 1998 ) that the cell group recognized as a superior preoptic nucleus in lungfishes and the Comoran coelacanth is homologous to part of the amygdalar complex in tetrapods. Based on the topology of this nucleus in the Comoran coelacanth, it appears homologous to the medial amygdalar nucleus of lungfishes and tetrapods. It therefore appears that all extant lobe-finned fishes are characterized by the same pattern of amygdalar organization, which may have arisen even earlier in gnathostome phylogeny.

\section{FUTURE DIRECTIONS}

In spite of the relatively large numbers of coelacanths that have been captured, the quality of the brain histology presently available is clearly marginal. If the specimen on which this analysis is primarily based were captured today, rather than some 38 years ago, it would be possible to use the numerous molecular markers now available, and our knowledge of coelacanth brain organization and brain phylogeny in lobe-finned fishes would be greatly increased. Every attempt should be made by comparative neurobiologists to proselytize coelacanth researchers so that they understand the importance of properly fixing brain tissue from an available specimen. At the same time, preservation of coelacanth habitats and the protection of these fascinating fishes is uppermost. It would be criminal if humanity allowed these ancient fishes to become extinct in our lifetime.

\section{ACKNOWLEDGMENTS}

This work was supported by the U.S. National Science Foundation (1BN-0919077), by The Spanish Ministry of Sciences and Education (BFU2009-12315), and by private funding.

forebrain of Xenopus laevis confirms a common pattern in tetrapods. $J$. Comp. Neurol. 461, 370-393.

Brox, A., Puelles, L., Ferreiro, B., and Medina, L. (2004). Expression of the genes Emxl, Tbr1 and Eomes (Tbr2) in the telencephalon of Xenopus laevis confirms the existence of four pallial divisions in tetrapods. J. Comp. Neurol. $474,562-577$. 
Bruton, M. N., and Coutouvidis, S. E. (1991). An inventory of all known specimens of the coelacanth Latimeria chalumnae, with comments on trends in the catches. Environ. Biol. Fishes 32, 371-390.

Fricke, H., Hissmann, K., Schauer, J., Reinicke, O., Kasang, L., and Plante, R. (1991). Habitat and population size of the coelacanth Latimeria chalumnae at Grand Comoro. Environ. Biol. Fishes 32, 287-300.

González, A., López, J. M., SánchezCamacho, C., and Márin, O. (2002). Regional expression of the homeobox gene NKX2-1 defines pallidal and interneuronal populations in the basal ganglia of amphibians. Neuroscience 114, 567-575.

González, A., Morona, R., López, J. M., Moreno, N., and Northcutt, R. G. (2010). Lungfishes, like tetrapods, possess a vomeronasal system. Front. Neuroanat. 4:130. doi: 10.3389/ fnana.2010.00130

González,A., and Northcutt, R. G. (2009). An immunohistochemical approach to lungfish telencephalic organization. Brain Behav. Evol. 74, 43-55.

Greenwood, H. (1987). "The natural history of African lungfishes," in The Biology and Evolution of Lungfishes, eds W. E. Bemis, W. W. Burggren, and N. E. Kemp (New York: Alan R. Liss, Inc.), 163-179.

Heimer, L., Zahm, D. S., and Alheid, G. F. (1995). "Basal ganglia," in The Rat Nervous System, ed. G. Paxinos (San Diego: Academic Press), 579-628.

Hissmann, K., Fricke, H., and Schauer, J. (1998). Population monitoring of the coelacanth (Latimeria chalumnae) Conserv. Biol. 12, 759-765.

Marín, O., Smeets, W. J.A. J., and González, A. (1998). Basal ganglia organization in amphibians: chemoarchitecture. J. Comp. Neurol. 392, 285-312.

Millot, J., and Anthony, J. (1958). Anatomie de Latimeria chalumnae. Tome I. Squelette, Muscles et Formations de Soutien. Paris: C.N.R.S., 122.

Millot, J., and Anthony, J. (1965). Anatomie de Latimeria chalumnae. Tome II. Système Nerveux et Organes des Sens. Paris: C.N.R.S., 131.

Millot, J., Anthony, J., and Robineau, D. (1978). Anatomie de Latimeria chalumnae. Tome III. Appareil Digestif, Appareil Respiratoire, Appareil Urogenital, Glandes Endocrine, Appareil Circulatoire, Tégujments, Écailles, Conclusions Générales. Paris: C.N.R.S., 198.

Moreno, N., Domínguez, L., Rétaux, S., and González, A. (2008). Islet 1 as a marker of subdivisions and cell types in the developing forebrain of Xenopus. Neuroscience 154, 1423-1439.

Moreno, N., and González, A. (2004). Localization and connectivity of the lateral amygdala in anuran amphibians. J. Comp. Neurol. 479, 130-148.

Moreno, N., and González, A. (2005). Central amygdala in anuran amphibians: neurochemical organization and connectivity. J. Comp. Neurol. 489, 69-91.

Moreno, N., and González, A. (2006). The common organization of the amygdaloid complex in tetrapods: new concepts based on developmental, hodological and neurochemical data in anuran amphibians. Prog Neurobiol. 78, 61-90.

Moreno, N., and González, A. (2007a) Regionalization of the telencephalon in urodele amphibians and its bearing on the identification of amygdaloid complex. Front. Neurosci. 1:1. doi: 10.3389/neuro.05/001.2007

Moreno, N., and González, A. (2007b). Development of the vomeronasal amygdala in anuran amphibians: hodological, neurochemical, and gene expression characterization. J. Comp. Neurol. 5023, 815-831.

Nieuwenhuys, R. (1965). The forebrain of the crossopterygian Latimeria chalumnae Smith. J. Morphol. 117 $1-24$.

Nieuwenhuys, R. (1998). “The coelacanth Latimeria chalumnae," in The Central Nervous System of Vertebrates, Vol.2, eds R. Nieuwenhuys, H. J. ten Donkelaar, and C. Nicholson (Heidelberg: Springer-Verlag), 1007-1043.

Nieuwenhuys, R., Kremers, J. P. M., and van Huijzen, C. (1977). The brain of the crossopterygian fish Latimeria chalumnae: a survey of its gross structure. Anat. Embryol. 151, 157-169.

Nieuwenhuys, R., and Meek, J. (1990) "The telencephalon of sarcopterygian fishes," in Cerebral Cortex, Vol. 8 A, Comparative Structure and Evolution of Cerebral Cortex, Part 1, eds E. G. Jones and A. Peters (New York: Plenum), 75-106.

Northcutt, R. G. (2009). Telencephalic organization in the spotted African lungfish, Protopterus dolloi: a new cytological model. Brain Behav. Evol. 73, 59-80.
Rudebeck, B. (1945). Contributions to forebrain morphology in Dipnoi. Acta Zool. 26, 9-157.

Takezaki, N., Figueroa, F., ZaleskaRutczynska, Z., Takahata, N., and Klein, J. (2004). The phylogenetic relationship of tetrapod, coelacanth, and lungfish revealed by the sequences of forty-four nuclear genes. Mol. Biol. Evol. 21, 1512-1524.

Wells, K. D. (2007). The Ecology and Behavior of Amphibians. Chicago: The University of Chicago Press.

Wicht, H., and Northcutt, R. G. (1992). The forebrain of the Pacific hagfish: a cladistic reconstruction of the ancestral craniate forebrain. Brain Behav. Evol. 40, 25-64.

Conflict of InterestStatement: The authors declare that the research was conducted in the absence of any commercial or financial relationships that could be construed as a potential conflict of interest.

Received: 08 November 2010; paper pending published: 06 December 2010; accepted: 14 February 2011; published online: 24 February 2011.

Citation: Northcutt RG and González A (2011) A reinterpretation of the cytoarchitectonics of the telencephalon of the Comoran coelacanth. Front. Neuroanat. 5:9. doi: 10.3389/fnana.2011.00009 Copyright (C) 2011 Northcutt and González. This is an open-access article subject to an exclusive license agreement between the authors and Frontiers Media SA, which permits unrestricted use, distribution, and reproduction in any medium, provided the original authors and source are credited. 